\title{
OPEN Oxidation suppression of $\mathrm{Cu}$ in alkaline aluminophosphate glass and the effects for radiation-induced luminescence characteristics
}

\author{
Daiki Shiratori $^{1 \bowtie}$, Hirokazu Masai $^{2}$, Takumi Kato ${ }^{1}$, Go Okada $^{3}$, Daisuke Nakauchi ${ }^{1}$, \\ Noriaki Kawaguchi ${ }^{1}$ \& Takayuki Yanagida $^{1}$
}

A glass phosphor is an attractive material for applications in radiation detections because of its high workability and availability with a wide range of chemical compositions. Recently, X-rayinduced luminescence of glasses containing various luminescent activators are actively investigated worldwide. In applications as phosphor, tailoring valence state of activators, which can take multiple valence states in glass, is very important. In this research, we studied effects of glass melting atmosphere on the valence state of copper-activator ion in alkaline aluminophosphate glasses and the radiation-induced luminescence characteristics. Optical absorption and X-ray absorption near edge structure spectra of Cu-doped glasses showed that the glass fused in Ar atmosphere contains higher concentration of $\mathrm{Cu}^{+}$than those prepared in air. In addition, the presence of $\mathrm{Cu}^{+}$enhances the photoluminescence $(\mathrm{PL})$ quantum yield and $\mathrm{PL}$ kinetic constant. Furthermore, the increase of $\mathrm{Cu}^{+}$ concentration resulted an improvement of the X-ray-induced scintillation and thermally-stimulated luminescence intensity.

Radiation detectors using fluorescent materials have been widely used today, for example, in personal dose monitoring ${ }^{1-4}$, medical diagnosis ${ }^{5-7}$, security ${ }^{8,9}$, high-energy physics ${ }^{10-12}$, environmental dose monitoring ${ }^{13,14}$, and oil logging ${ }^{15}$. Typically, such fluorescent materials are used to convert high energy ionizing radiation into low energy photons ${ }^{16}$ so that the radiation is detected indirectly by reading the converted photons with a photodetector. The material forms of practical radiation detectors are mainly single crystal and ceramic, and glass is seldom used although it has great advantages compared with single crystal and ceramic. For instance, glass has high workability and can be mass-produced easily, and a wide range of chemical compositions are available. Therefore, glass is an attractive candidate for a new fluorescent material to replace existing materials for radiation detection.

Our group has investigated radiation-induced luminescence properties of various phosphate glasses doped with a range of luminescent activators ${ }^{17-20}$. Among these researches, we have focused on $\mathrm{Cu}^{+}$as a luminescence center element since $\mathrm{Cu}$-doped phosphors generally show blue emission due to the $3 \mathrm{~d}^{9} 4 \mathrm{~s}^{1}-3 \mathrm{~d}^{10}$ transition of $\mathrm{Cu}^{+}$, of which the luminescence wavelength agreed well with the spectral sensitivity of common photodetectors. In contrast, it is known that divalent copper does not show emission in the spectral region detectable by conventional photodetectors, and, in fact, $\mathrm{Cu}$ ion is likely in a divalent state in a fused glass due to redox reactions. Therefore, to enhance the functionalities as a fluorescent material, it is necessary to prepare the glass with a luminescent activator ion taking the desired valence state $\left(\mathrm{Cu}^{+}\right.$in case of $\mathrm{Cu}$-doped materials). One of the methods to prevent the formation of $\mathrm{Cu}^{2+}$ in glass is to synthesize under a reducing atmosphere during a melting process. In this study, we attempted a suppression of the presence of $\mathrm{Cu}^{2+}$ in glass by substituting the molten atmosphere inside a $\mathrm{SiO}_{2}$ tammann tube with an inert gas. The glass composition in this study was $\mathrm{Li}_{2} \mathrm{O}-\mathrm{K}_{2} \mathrm{O}-\mathrm{Al}_{2} \mathrm{O}_{3}-\mathrm{P}_{2} \mathrm{O}_{5}$ system, where $\mathrm{Li}_{2} \mathrm{O}$ was added to potassium phosphate glass system in order to lower the softening point of the glass because the critical operating temperature of $\mathrm{SiO}_{2}$ tammann tubes is about $1100^{\circ} \mathrm{C}$.

${ }^{1}$ Nara Institute of Science and Technology, 8916-5 Takayama, Ikoma, Nara 630-0192, Japan. ${ }^{2}$ National Institute of Advanced Industrial Science and Technology, 1-8-31 Midorigaoka, Ikeda, Osaka 563-8577, Japan. ${ }^{3}$ Kanazawa Institute of Technology, 3-1 Yatsukaho, Hakusan, Ishikawa 924-0838, Japan. ${ }^{\varpi}$ email: shiratori.daiki.sc3@ ms.naist.jp 


\begin{tabular}{|l|l|}
\hline Glass specimens & $\boldsymbol{T}_{\mathrm{g}}\left({ }^{\circ} \mathbf{C}\right)$ \\
\hline $\mathrm{Cu}(0.00 \%)-\mathrm{Ar}$ & 455 \\
\hline $\mathrm{Cu}(0.01 \%)-\mathrm{Ar}$ & 456 \\
\hline $\mathrm{Cu}(0.05 \%)-\mathrm{Ar}$ & 455 \\
\hline $\mathrm{Cu}(0.10 \%)-\mathrm{Ar}$ & 453 \\
\hline $\mathrm{Cu}(0.00 \%)$-air & 457 \\
\hline $\mathrm{Cu}(0.01 \%)$-air & 446 \\
\hline $\mathrm{Cu}(0.05 \%)$-air & 443 \\
\hline $\mathrm{Cu}(0.10 \%)$-air & 442 \\
\hline
\end{tabular}

Table 1. Glass transition temperature $T_{\mathrm{g}}$ of all the specimens from DTA measurement.

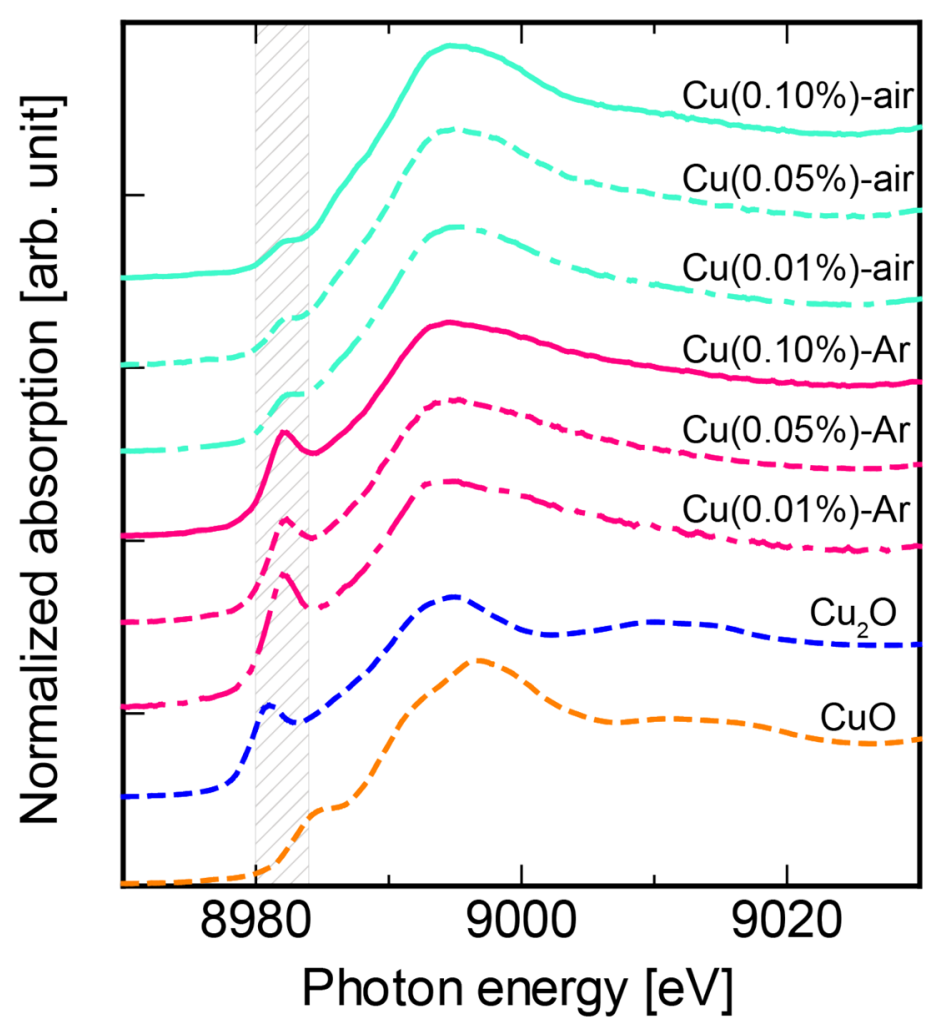

Figure 1. $\mathrm{Cu}$ K-edge XANES spectra of the $\mathrm{Cu}$-doped specimens, $\mathrm{CuO}$, and $\mathrm{Cu}_{2} \mathrm{O}$.

The aim of the present study is to investigate the relationship between X-ray-induced luminescence characteristics and the melting atmosphere of $\mathrm{Cu}$-doped glasses. Different melting conditions may cause the emission properties to change based on the redox state of the cation. Based on results of X-ray absorption near edge structure (XANES) analyses of the valence of $\mathrm{Cu}$ ions in the glass, correlations between glass melting conditions and optical and X-ray-induced luminescence properties are also discussed.

\section{Results}

The density and thickness of all the specimens are shown in Figure S1. From the XRD measurement results, only a halo peak which is a characteristic of glass was observed, and no crystallization was confirmed (Figure S1). Thermal properties of all the specimens examined by differential thermal analysis (DTA) are shown in Table 1 and Figure S2. Each specimen exhibited an endotherm corresponding to $T_{\mathrm{g}}$ at around $450{ }^{\circ} \mathrm{C}$, followed by another endotherm corresponding to the re-melting of glass matrix. Thermal annealing was performed for all the glass specimens at the corresponding $T_{\mathrm{g}}$ temperature to remove the internal stress. The $T_{\mathrm{g}}$ of the $\mathrm{Cu}$-Ar specimens were higher than those of the $\mathrm{Cu}$-air, suggesting that their thermal properties were different by the melting atmosphere.

Figure 1 shows normalized $\mathrm{Cu}$ K-edge XANES spectra of the $\mathrm{Cu}$-doped specimens. $\mathrm{CuO}$ and $\mathrm{Cu}_{2} \mathrm{O}$ are reference raw compounds of divalent and monovalent $\mathrm{Cu}$, respectively, and we estimated the valence state of $\mathrm{Cu}$ in the specimens compared with these references. The $\mathrm{Cu}$-Ar specimen and $\mathrm{Cu}_{2} \mathrm{O}$ had a distinct pre-edge around $8981 \mathrm{eV}$ which was assigned to the $1 \mathrm{~s}-4 \mathrm{p}$ electronic transition of $\mathrm{Cu}^{21,22}$. In contrast, we observed only a shoulder 


\begin{tabular}{|c|c|c|c|}
\hline Glass specimens & QYs (\%) & Valence ratio $\left(\mathrm{Cu}^{+} / \mathrm{Cu}_{\text {total }}\right)(\%)$ & $\mathrm{Cu}^{+}$concentration $(\mathrm{mol} \%)$ \\
\hline $\mathrm{Cu}(0.01 \%)-\mathrm{Ar}$ & 19.0 & 89 & 0.0089 \\
\hline $\mathrm{Cu}(0.05 \%)-\mathrm{Ar}$ & 28.3 & 61 & 0.0305 \\
\hline $\mathrm{Cu}(0.10 \%)-\mathrm{Ar}$ & 31.1 & 67 & 0.067 \\
\hline $\mathrm{Cu}(0.01 \%)$-air & 5.5 & 21 & 0.0021 \\
\hline $\mathrm{Cu}(0.05 \%)$-air & 4.8 & 11 & 0.0055 \\
\hline $\mathrm{Cu}(0.10 \%)$-air & 2.3 & 7 & 0.007 \\
\hline
\end{tabular}

Table 2. $\mathrm{PL} Q Y$ s, valence ratio, and relative $\mathrm{Cu}^{+}$concentration in the all $\mathrm{Cu}$-doped specimens.

structure in the spectra of the $\mathrm{Cu}$-air specimen and $\mathrm{CuO}$. It has been recognized that the pre-edge feature corresponds to the absorption edge of $\mathrm{Cu}^{+}$, but $\mathrm{Cu}^{2+23-25}$. These results indicate that the $\mathrm{Cu}$-Ar specimen includes most of the $\mathrm{Cu}$ in the monovalent state while most $\mathrm{Cu}$ ions in the $\mathrm{Cu}$-air specimen was present in the divalent state.

We also estimated the valence state of each $\mathrm{Cu}$-doped specimen quantitatively by the linear combination fitting method using Athena program. In the linear combination fitting method, the X-ray absorption spectrum is approximated by a least-square fitting with a linear combination of spectra of known species. The linear combination fitting has been carried out for the normalized spectrum in the range from 8970 to $9020 \mathrm{eV}$ in this analysis. The fitted spectra and calculated results are shown in the Figure S3 and Table 2. Here, we assumed that all the $\mathrm{Cu}$ ions take a state of either $\mathrm{CuO}\left(\mathrm{Cu}^{2+}\right)$ or $\mathrm{Cu}_{2} \mathrm{O}\left(\mathrm{Cu}^{+}\right)$, and $\mathrm{Cu}_{\text {total }}$ is defined as a total number of $\mathrm{Cu}$ ions (i.e. sum the numbers of $\mathrm{Cu}^{2+}$ and $\mathrm{Cu}^{+}$ions). Comparing between the two different specimens prepared in $\mathrm{Ar}$ and air (both are doped with $0.01 \% \mathrm{Cu}$ ), the former includes approximately $90 \%$ of $\mathrm{Cu}$ ion in the monovalent state while only $20 \%$ was found in the latter specimen.

Figure 2 shows the optical absorption spectra in the UV and near infrared (NIR) regions for the specimens prepared under $(\mathrm{a}, \mathrm{b})$ Ar and (c,d) air. In the undoped specimens, an absorption band feature was observed in the UV region at around $220 \mathrm{~nm}$ (Fig. 2a,c). The absorption is originated from unavoidable trace Fe impurities included in the raw starting materials of the glasses ${ }^{26,27}$. For the $\mathrm{Cu}$-doped specimens, an absorption band appeared near $250 \mathrm{~nm}$. The latter absorption band is assigned to $3 \mathrm{~d}^{10}-3 \mathrm{~d}^{9} 4 \mathrm{~s}^{1}$ transition of $\mathrm{Cu}^{+28}$. The absorption bands shift to longer wavelength with increasing the $\mathrm{Cu}$ concentration. Moreover, the absorption band of the $\mathrm{Cu}$-air specimen appeared on the longer wavelength side than that of the $\mathrm{Cu}$-Ar specimen. This behavior is not attributed to the presence of the $3 \mathrm{~d}^{10}-3 \mathrm{~d}^{9} 4 \mathrm{~s}^{1}$ transition of $\mathrm{Cu}^{+}$but a charge transfer of $\mathrm{O}-\mathrm{Cu}-\mathrm{O}$ complex ${ }^{29,30}$, which implies that the generation of $\mathrm{O}-\mathrm{Cu}-\mathrm{O}$ is suppressed when the glass is molten in Ar atmosphere. Figure $2 \mathrm{~b}, \mathrm{~d}$ are the absorption spectra in the NIR range. The $\mathrm{Cu}$-air specimens showed more remarkable absorption band near $800 \mathrm{~nm}$ than those of the $\mathrm{Cu}$-Ar specimens, and any absorption band was not confirmed in the undoped specimens. This absorption band is considered to be due to ${ }^{2} \mathrm{E}_{\mathrm{g}}-{ }^{2} \mathrm{~T}_{\mathrm{g}}$ transition of $\mathrm{Cu}^{2+}$ placed in an distorted octahedral field ${ }^{30-32}$. This result suggests that $\mathrm{Cu}^{2+}$ can be present in a large proportion when the glass was molten in air atmosphere compared with those molten in Ar atmosphere. In other words, the melting under the $\mathrm{Ar}$ atmosphere can increase the concentration of $\mathrm{Cu}^{+}$. These observations in the absorption spectra as a function of $\mathrm{Cu}$ concentration are consistent with those by the linear combination fittings of the XANES spectra. On the other hand, these results also suggest that oxidation does somewhat occurred even when the material was molten in Ar atmosphere. We assume that the oxidation reaction occurred during the quenching process since it was performed in air, although we ensured the glass melt to be exposed to air as short time as possible during the quenching process. An increase in absorbance observed in the region longer than $2500 \mathrm{~nm}$ is due to absorption by $\mathrm{OH}$ stretching ${ }^{17}$. The absorption attributed to $\mathrm{OH}$ stretching was more remarkable in those molten in air than Ar.

Figure 3a shows photoluminescence (PL) excitation/emission spectra of the $0.10 \% \mathrm{Cu}$-doped specimens at room temperature (R.T.), and PL excitation/emission contour maps and spectra of all the Cu-doped specimens are also shown in Figure S4 and S5. Each specimen had a broad excitation band in the UV region and showed a broad emission band peaking at around $440 \mathrm{~nm}$. This emission is due to the $3 \mathrm{~d}^{9} 4 \mathrm{~s}^{1}-3 \mathrm{~d}^{10}$ transition of $\mathrm{Cu}^{+31}$. Here, we observed a spectral peak shift in the excitation spectra of the $\mathrm{Cu}$-air specimens more effectively than those of the $\mathrm{Cu}$-Ar specimens. The shift in excitation spectra is because the $\mathrm{Cu}$-air specimens have an absorption band due to the $\mathrm{O}-\mathrm{Cu}-\mathrm{O}$ complexes in addition to the $3 \mathrm{~d}^{10}-3 \mathrm{~d}^{9} 4 \mathrm{~s}^{1}$ band, which overlaps with a part of the excitation band. In contrast, we did not observe a spectral peak shift of an emission band in all the Cu-doped specimens (see Figure S5). In the emission spectra, all the specimens indicated a weak shoulder feature on the longer wavelength side (around 450-500 nm), which suggests that the emission has two different origins. Figure 3b,c show peak deconvolution results by gaussian fitting of $0.10 \% \mathrm{Cu}-\mathrm{Ar}$ and $\mathrm{Cu}$-air. Each spectrum was well-reproduced by a convolution of two gaussians peaking at 424 and $467 \mathrm{~nm}$. Figure $3 \mathrm{~d}$ is a ratio of the integrated gaussians $(424 / 467 \mathrm{~nm})$ as a function of $\mathrm{Cu}$ concentration. The PL band peaking at $424 \mathrm{~nm}$ was dominant than the other for all the specimens. In addition, an anticorrelation of the emission ratio was observed between the specimens molten under Ar and air atmospheres. This fact suggests that glass melting atmosphere controls the coordination environment around $\mathrm{Cu}^{+}$. The emission origins of these bands will be discussed in detail below together with the results of PL decay constants.

The maximum PL quantum yields (QY) for emission by $\mathrm{Cu}^{+}$are summarized in Table 2. The $Q Y$ of each specimen showed a maximum value when excited at $250 \mathrm{~nm}$. The $Q Y$ was significantly higher in the $\mathrm{Cu}-\mathrm{Ar}$ specimens than the $\mathrm{Cu}$-air specimens. These results fully reflected the effect of melting in Ar atmosphere. Furthermore, the $Q Y$ of $\mathrm{Cu}$-Ar tended to increase with increasing $\mathrm{Cu}$ concentration while it tended to decrease for $\mathrm{Cu}$-air 
(a)

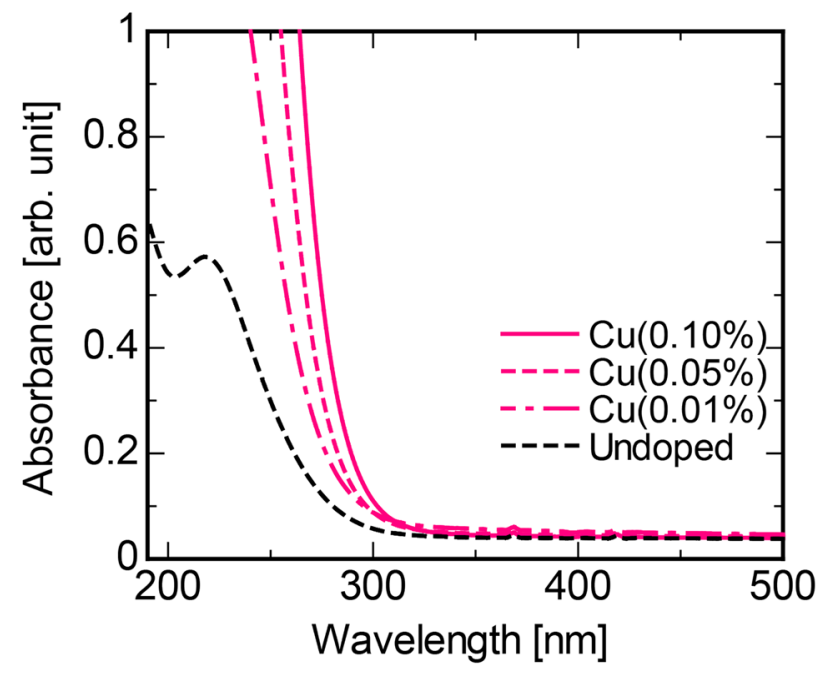

(c)

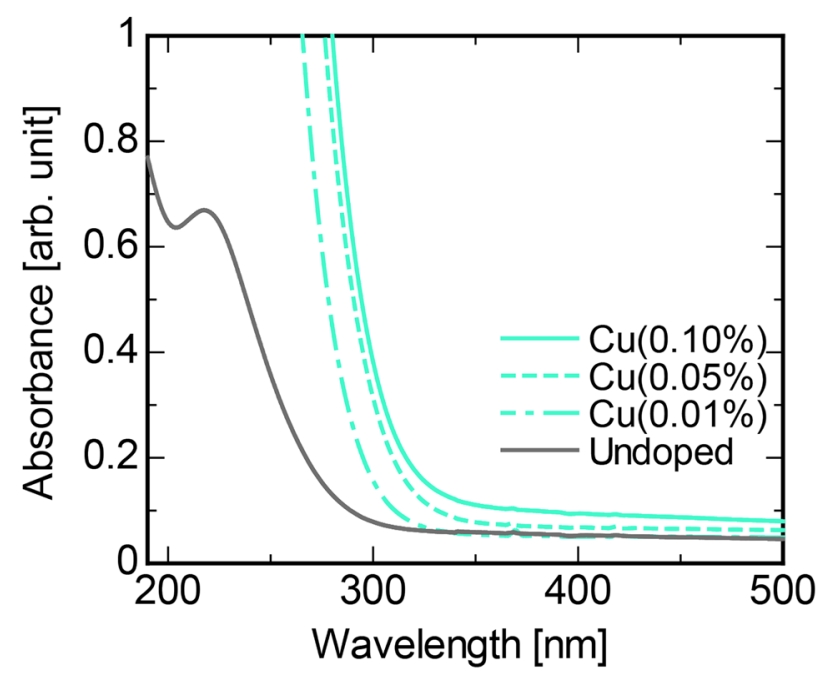

(b)

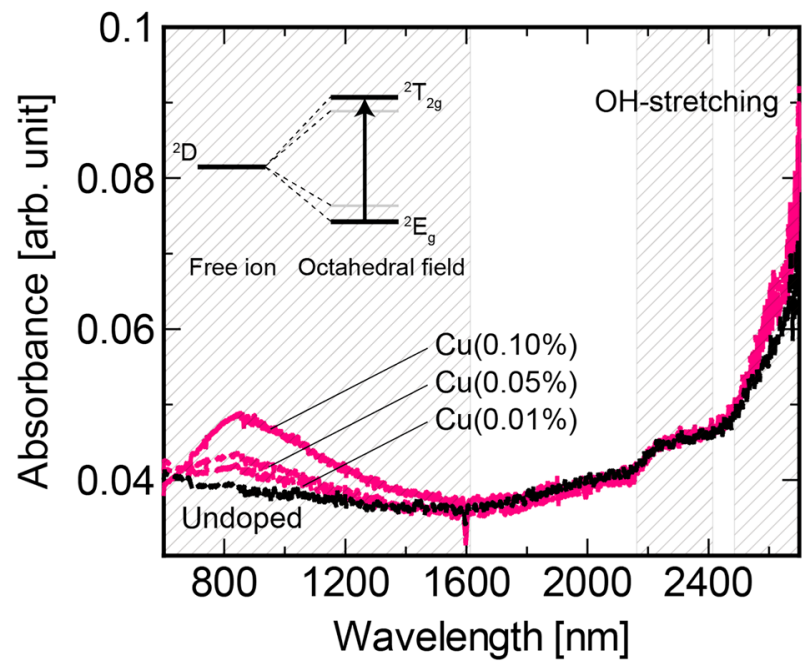

(d)

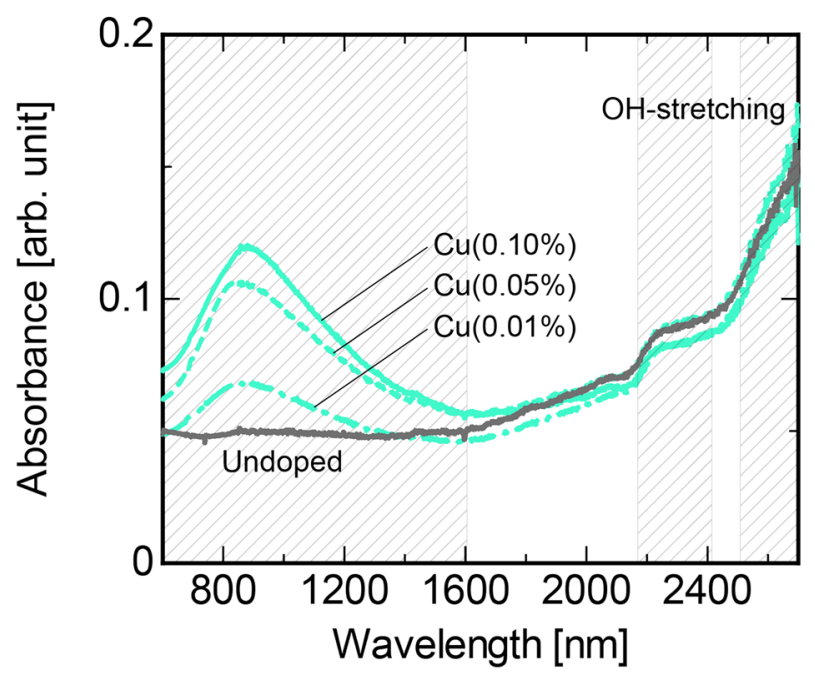

Figure 2. Absorption spectra of all specimens. UV and NIR region absorption spectra of the specimens prepared under $(\mathbf{a}, \mathbf{b})$ Ar and $(\mathbf{c}, \mathbf{d})$ air atmosphere.

specimens. Figure 4 is a correlation between $Q Y$, valence ratio $\left(\mathrm{Cu}^{+} / \mathrm{Cu}_{\text {total }}\right)$, and $\mathrm{Cu}^{+}$concentration as a function of doping concertation of $\mathrm{Cu}$. The valence ratio calculated from the linear combination fitting analysis of XANES spectra tends to decrease with increasing the $\mathrm{Cu}$ concentration (except for $\mathrm{Cu}(0.10 \%)$ - Ar), while the actual $\mathrm{Cu}^{+}$ concentration increases with $\mathrm{Cu}$ concentration. Focusing on the relationship between $\mathrm{Cu}^{+}$and $\mathrm{QY}$, we can see that there is a positive correlation in the $\mathrm{Cu}$-Ar specimens and a negative correlation in $\mathrm{Cu}$-air.

Figures 5 represents PL decay features of the (a) $\mathrm{Cu}$-Ar and (b) $\mathrm{Cu}$-air specimens, and the obtained PL lifetime constants are summarized in Table 3. The excitation and monitored wavelengths were 260 and $440 \mathrm{~nm}$, respectively. PL lifetimes were deduced by approximating the experimental data with a sum of two exponential decay functions. The calculated decay constants were on an order of several tens of microseconds, and the experimental results agreed well with the previously reported values of luminescence by $\mathrm{Cu}^{+}$activator ${ }^{33}$. According to a previous study, in case of amorphous materials such as glass, the triplet state $\left({ }^{3} \mathrm{E}_{\mathrm{g}}\right)$ of the $3 \mathrm{~d}^{9} 4 \mathrm{~s}^{1}$ configuration, which is an excited state of $\mathrm{Cu}^{+}$, is split into two levels $\left(\mathrm{T}_{2 \mathrm{~g}}\right.$ and $\left.\mathrm{T}_{1 \mathrm{~g}}\right)$ because the $\mathrm{Cu}$ coordinates at the distorted tetrahedral sites ${ }^{33}$. The first and second components of the PL lifetime are assigned to the emission transitions from the triplet states $\mathrm{T}_{2 \mathrm{~g}}$ and $\mathrm{T}_{1 \mathrm{~g}}$ to the ${ }^{1} \mathrm{~A}_{1 \mathrm{~g}}$ ground state, respectively. The two PL peaks at 424 and $467 \mathrm{~nm}$ correspond to the emissions by transitions from $\mathrm{T}_{2 \mathrm{~g}}$ and $\mathrm{T}_{1 \mathrm{~g}}$, respectively. Figure $5 \mathrm{c}, \mathrm{d}$ are PL decay constants, and kinetic constants as a function of the $\mathrm{Cu}$ concentration of $\mathrm{Cu}-\mathrm{Ar}$ and $\mathrm{Cu}$-air specimens. Here, the kinetic constant is a probability of radiative transition per unit time and is denoted as $k_{\mathrm{r}}$ in this paper. Furthermore, if the probability of the non-radiative transition is defined as $k_{\mathrm{nr}}$, the decay constant can be expressed as $\tau=1 /\left(k_{\mathrm{r}}+k_{\mathrm{nr}}\right)$. 
(a)

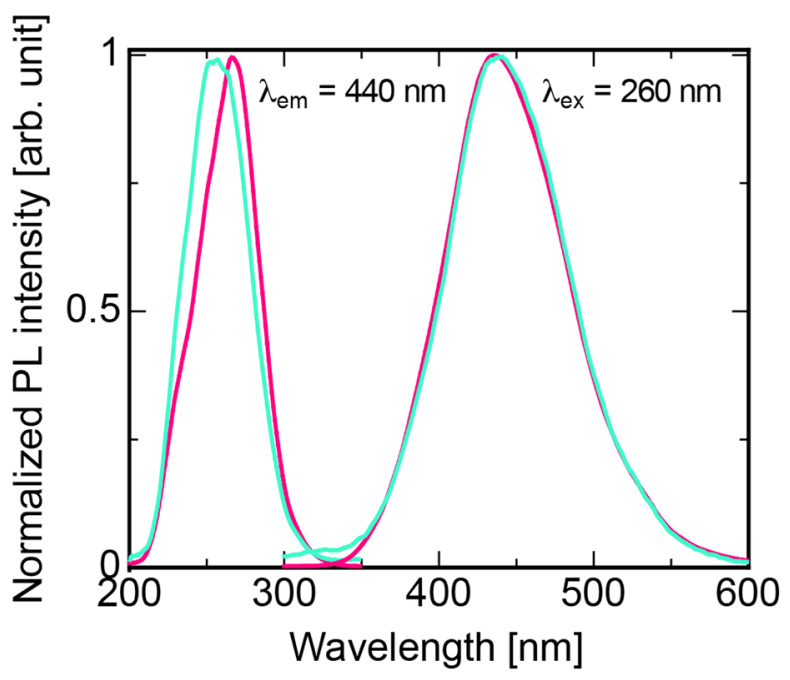

(c)

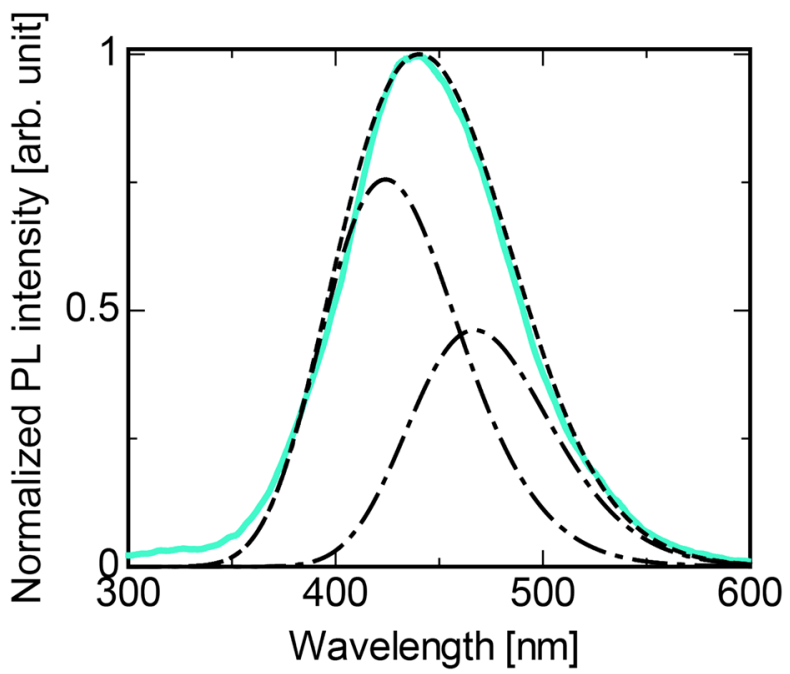

(b)

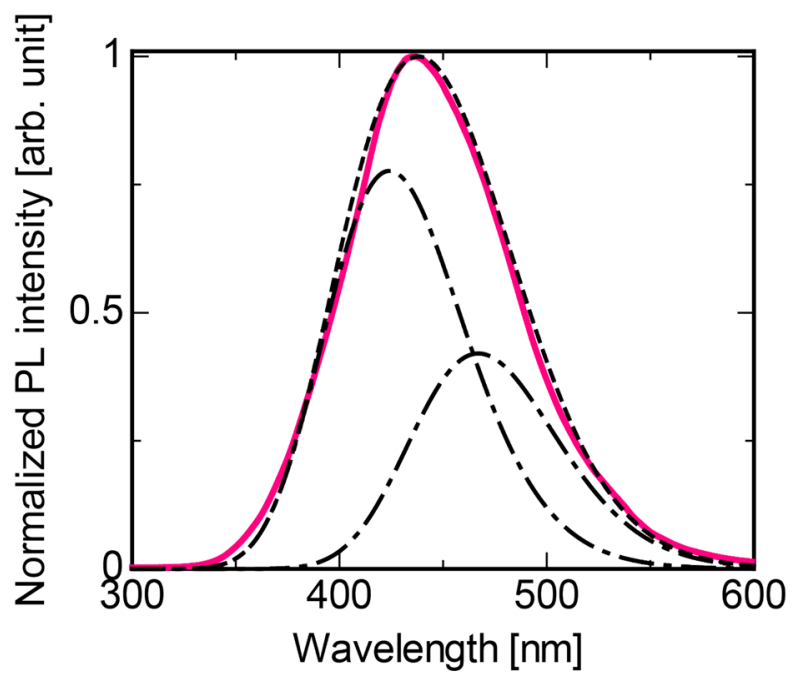

(d)

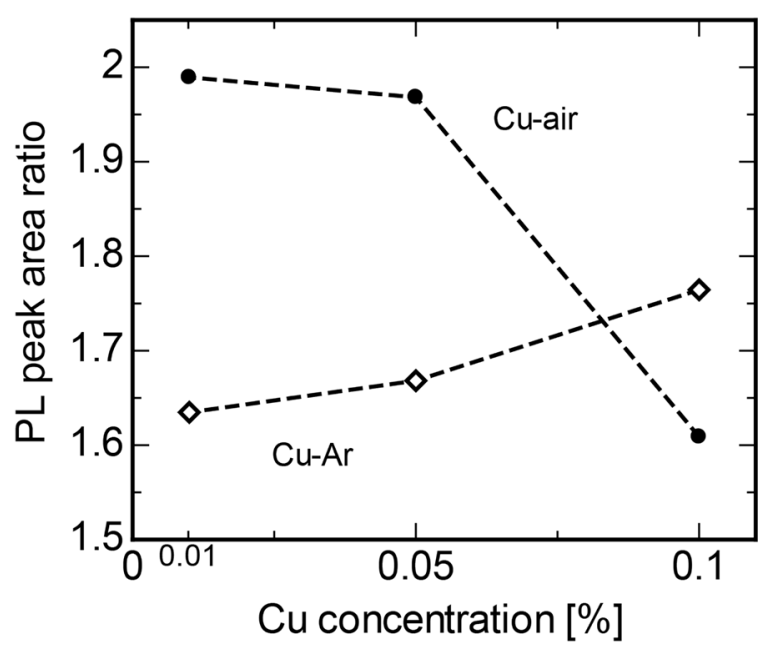

Figure 3. PL excitation/emission spectra of the specimens. (a) PL excitation/emission spectra of $0.10 \%$ $\mathrm{Cu}$-doped specimens. The monitored and excitation wavelength were $440 \mathrm{~nm}$ and $260 \mathrm{~nm}$, respectively. PL spectrum of $(\mathbf{b}) \mathrm{Cu}(0.10 \%)$ - Ar and (c) $\mathrm{Cu}(0.10 \%)$-air specimens fitted by double gaussians. (d) Ratio of the spectral area with a peak at $424 \mathrm{~nm}$ to the spectral area with a peak at $467 \mathrm{~nm}$.

In addition, a PL $Q Y$ is expressed using these kinetic constants as $Q Y=k_{\mathrm{r}} /\left(k_{\mathrm{r}}+k_{\mathrm{nr}}\right)$. From these relationships, the kinetic constant can be calculated by the following equation.

$$
k r=Q Y / \tau .
$$

There was a positive correlation between $\mathrm{Cu}$ concentration and PL decay constants or kinetic constants of each $\mathrm{Cu}$-Ar specimen. In contrast, we confirmed a negative correlation in $\mathrm{Cu}$-air. This result suggests that the $\mathrm{Cu}^{+}$concentration increases with increasing $\mathrm{Cu}$ concentration for $\mathrm{Cu}-\mathrm{Ar}$ whereas it decreases with increasing $\mathrm{Cu}$ concentration in $\mathrm{Cu}$-air.

Figure 6 shows X-ray-induced scintillation spectra of (a) Cu-Ar and (b) Cu-air specimens, and (c) a relationship between PL QY, the $\mathrm{Cu}^{+}$concentration, and the scintillation peak area as a function of effective atomic number ( $Z_{\text {eff: }}$ explained in the discussion section) and $\mathrm{Cu}$ concentration. In each undoped specimen, we observed a weak broad emission from 300 to $500 \mathrm{~nm}$ with a peak around $320 \mathrm{~nm}$. The latter broad emission is attributed to intrinsic luminescence center called L-center in glass ${ }^{34-36}$. In the case of our specimens, this L-center is interpreted as $\mathrm{P}-\mathrm{O}-\mathrm{K}$ linkages ${ }^{34,37}$. In contrast, $\mathrm{Cu}$-doped glass specimens melted both in $\mathrm{Ar}$ and air had different emission peak features from the undoped ones. Following the spectral shapes of the PL from Cu-doped specimen, we 


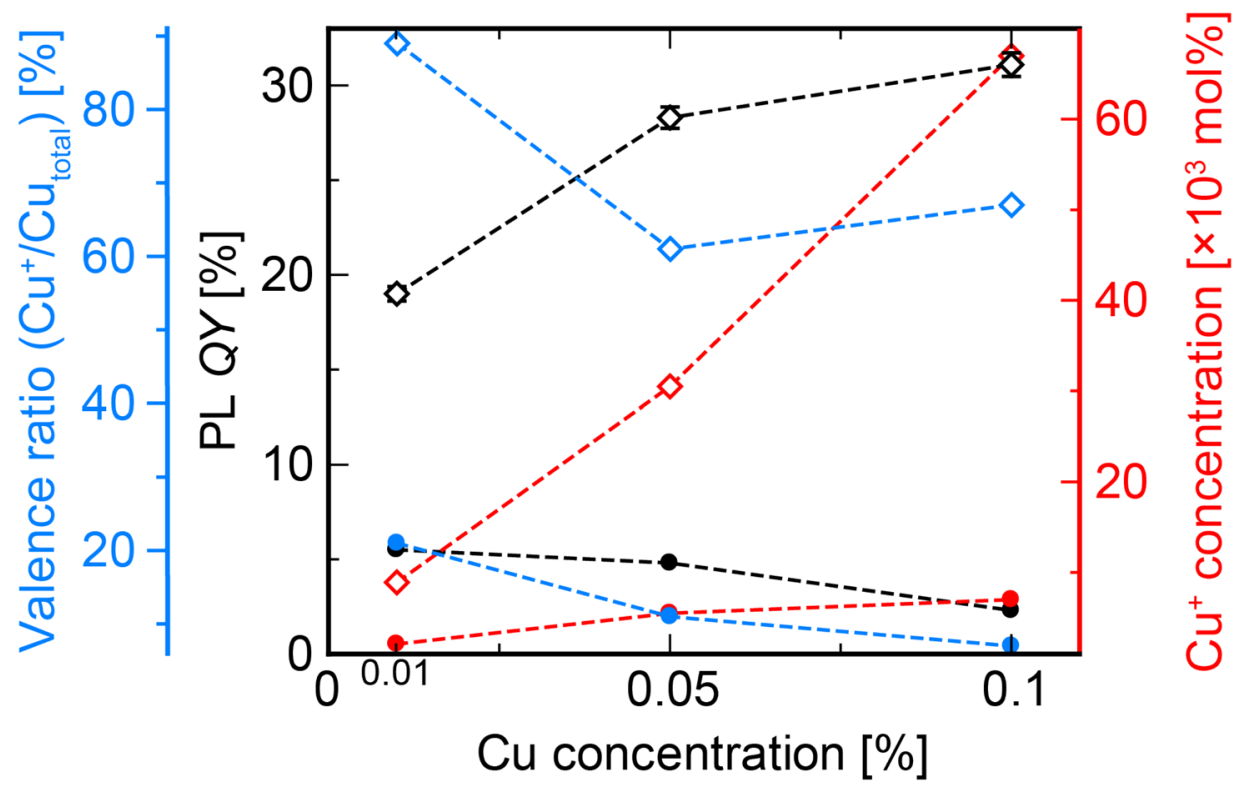

Figure 4. Correlation of $\mathrm{PL} Q Y$, valence ratio $\left(\mathrm{Cu}^{+} / \mathrm{Cu}_{\text {total }}\right)$, and $\mathrm{Cu}^{+}$concentration value as a function of $\mathrm{Cu}$ concentration. Open and closed symbols indicate $\mathrm{Cu}-\mathrm{Ar}$ and $\mathrm{Cu}$-air specimen, respectively.

could attribute the origin of scintillation emission to the $3 \mathrm{~d}^{9} 4 \mathrm{~s}^{1}-3 \mathrm{~d}^{10}$ transition of $\mathrm{Cu}^{+}$. Focusing on the peak position, we can see that these scintillation peak positions are longer than those of PL. Furthermore, the peak wavelength of the $\mathrm{Cu}$-air is longer than that of the $\mathrm{Cu}$-Ar specimens (see Figure $\mathrm{S} 6$ ). Based on a previous report, the reason is probably because an emission peak due to $\mathrm{Cu}^{+}-\mathrm{Cu}^{+}$dimer appeared in scintillation ${ }^{38}$. The trend of increasing or decreasing scintillation emission area is positively correlated with $Q Y$ among the $\mathrm{Cu}-\mathrm{Ar}$ specimens. In contrast, it was negatively correlated with $Q Y$ among the $\mathrm{Cu}$-air specimens.

Thermally stimulated luminescence (TSL) glow curve represents luminescence intensity as a function of temperature while heating at a constant rate. Prior to the measurement, the specimens were irradiated with X-rays of $10 \mathrm{~Gy}$. The obtained glow curves are illustrated in Fig. 7a-c. We could observe two glow peaks from the undoped specimens. Following the results from scintillation, the luminescence center in TSL of the undoped specimens seems to be the L-center. On the other hand, the $\mathrm{Cu}$-doped specimens showed only a single glow peak, and its intensity significantly increased compared with the undoped specimens. Both $\mathrm{Cu}-\mathrm{Ar}$ and $\mathrm{Cu}$-air types had a glow peak nearby $110^{\circ} \mathrm{C}$, and no significant differences in the glow curve shape was observed regardless of the difference of the melting atmosphere. It is assumed that the luminescence center in TSL of the Cu-doped specimens is the $3 \mathrm{~d}^{9} 4 \mathrm{~s}^{1}-3 \mathrm{~d}^{10}$ transition of $\mathrm{Cu}^{+}$. Figure $7 \mathrm{~d}$ shows the PL QY and normalized TSL intensity as a function of $\mathrm{Cu}$ concentration. In the $\mathrm{Cu}$ - $\mathrm{Ar}$ specimens, the fluctuation trend of the normalized TSL intensity coincides with $Q Y$. In the $\mathrm{Cu}$-air specimens, both $Q Y$ and normalized TSL intensity showed a decreasing trend from 0.01 to $0.05 \%$ while, from 0.05 to $0.10 \%$, QY decreased and normalized TSL intensity increased.

\section{Discussion}

First, we discuss the physical properties of the glass specimens. In the TG-DTA measurements, $T_{\mathrm{g}}$ of Cu-doped specimens exhibit different tendency depending on the preparation atmosphere. Although $T_{\mathrm{g}}$ of Cu-doped glass decreases with increasing $\mathrm{Cu}$ concentration, the specimens prepared in air atmosphere possess steeper change compared with those prepared in Ar atmosphere. Considering the present results, we assume that $\mathrm{Cu}^{2+}$ species are more effective than $\mathrm{Cu}^{+}$to decrease the $T_{\mathrm{g}}$. We could not confirm metallic $\mathrm{Cu}$ related spectrum from the optical absorption and $\mathrm{Cu}$ K-edge XANES spectra. Therefore, our glass specimens have not included metallic $\mathrm{Cu}$.

It should be noted that the results of linear combination fitting of the XANES spectra are for reference only because the host material of the fitted spectra is different from that of the reference samples. As illustrated in Fig. 5c,d, PL QYs, decay constants and kinetic constants are correlated with Cu concentration. Therefore, actually, the concentration of $\mathrm{Cu}^{+}$in $\mathrm{Cu}$-air is expected to decrease even more strongly with $\mathrm{Cu}$ concentration, and the $\mathrm{Cu}^{+}$concentration is expected to show the same decreasing trend as in $Q Y$. Based on the above observations, we will discuss the results of X-ray-induced luminescence properties.

When $\mathrm{X}$ or $\gamma$ rays pass through a material with atomic number $Z$, the incident radiation decreases exponentially with the penetration depth whose degree is well-defined with a linear attenuation coefficient. The linear attenuation coefficient is proportional to the fourth power of $Z$, since the photoelectric effect is dominant in the case of X-rays with energy of several tens of $\mathrm{keV}$, which is also the case of this research. If the substance is a compound, it is expressed as a sum of the linear attenuation coefficient weighted in weight fractions of each constituent element. In other words, the fourth power of the compound atomic number $Z_{\text {eff }}$ corresponds to the total sum of products of the weight fraction of each element and the fourth power of respective constituent elements, we can calculate $Z_{\text {eff }}$ by taking these biquadratic roots. In the present glass composition, an increase in the 
(a)

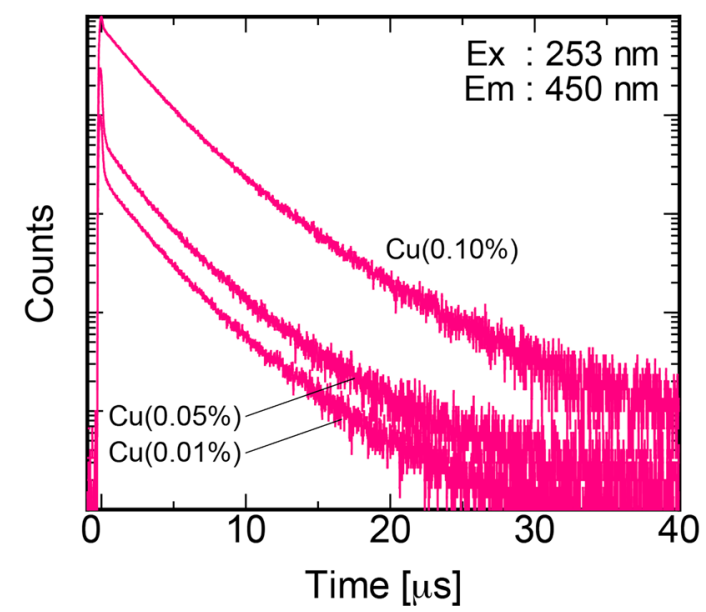

(c)

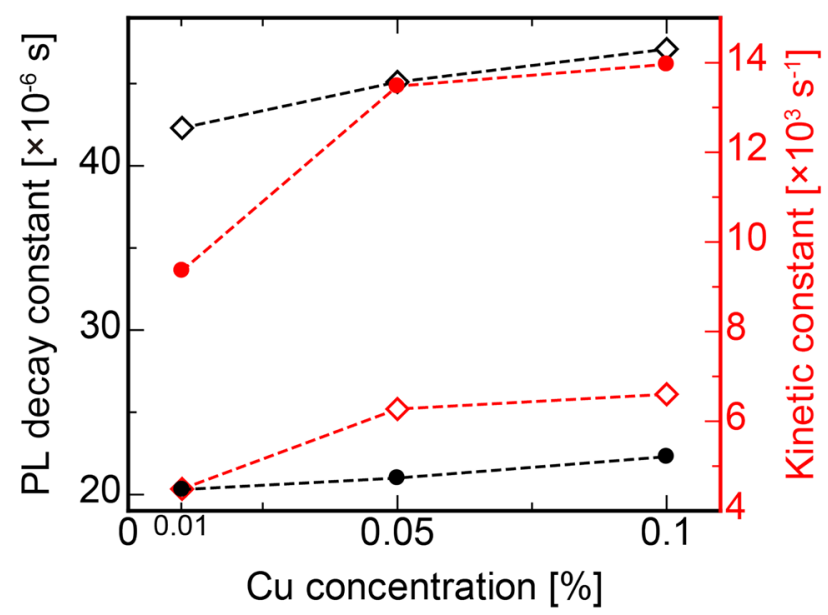

(b)

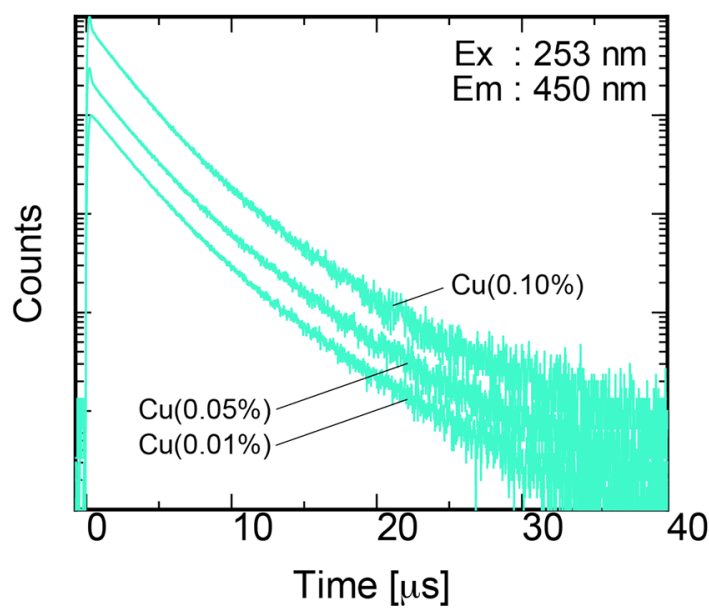

(d)

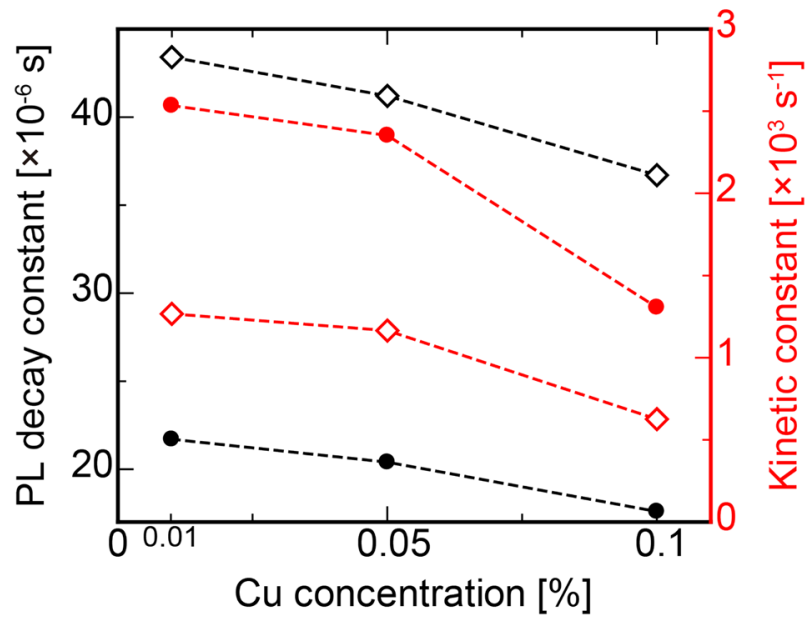

Figure 5. PL decay properties of all the specimens. PL decay curves of the (a) $\mathrm{Cu}$ - $\mathrm{Ar}$ and (b) $\mathrm{Cu}$-air specimens. Values of PL decay constants, and kinetic constants as a function of the $\mathrm{Cu}$ concentration of the (c) $\mathrm{Cu}-\mathrm{Ar}$ and (d) Cu-air specimens. The excitation and monitored wavelength set $260 \mathrm{~nm}$ and $440 \mathrm{~nm}$. Open squares and closed circles indicate first and second components of each PL decay constants and kinetic constants, respectively.

\begin{tabular}{|c|c|c|c|c|}
\hline \multirow[b]{2}{*}{ Glass specimens } & \multicolumn{2}{|c|}{$\begin{array}{l}\text { PL decay } \\
\text { constant } \tau \\
(\mu s)\end{array}$} & \multicolumn{2}{|c|}{$\begin{array}{l}\text { Kinetic } \\
\text { constant } k_{\mathrm{r}}\left(\mathrm{s}^{-1}\right)\end{array}$} \\
\hline & 1st & 2nd & 1st & 2nd \\
\hline $\mathrm{Cu}(0.01 \%)-\mathrm{Ar}$ & 20.3 & 42.3 & 9.359 & 4.491 \\
\hline $\mathrm{Cu}(0.05 \%)-\mathrm{Ar}$ & 21.0 & 45.1 & 13.476 & 6.274 \\
\hline $\mathrm{Cu}(0.10 \%)-\mathrm{Ar}$ & 22.3 & 47.1 & 13.946 & 6.603 \\
\hline $\mathrm{Cu}(0.01 \%)$-air & 21.7 & 43.4 & 2.534 & 1.267 \\
\hline $\mathrm{Cu}(0.05 \%)$-air & 20.4 & 41.2 & 2.352 & 1.165 \\
\hline $\mathrm{Cu}(0.10 \%)$-air & 17.6 & 36.7 & 1.306 & 0.626 \\
\hline
\end{tabular}

Table 3. PL decay and kinetic constants of the $\mathrm{Cu}$-doped specimens. The excitation wavelength was $260 \mathrm{~nm}$ which was cut off from light source by using optical filter. 
(a)

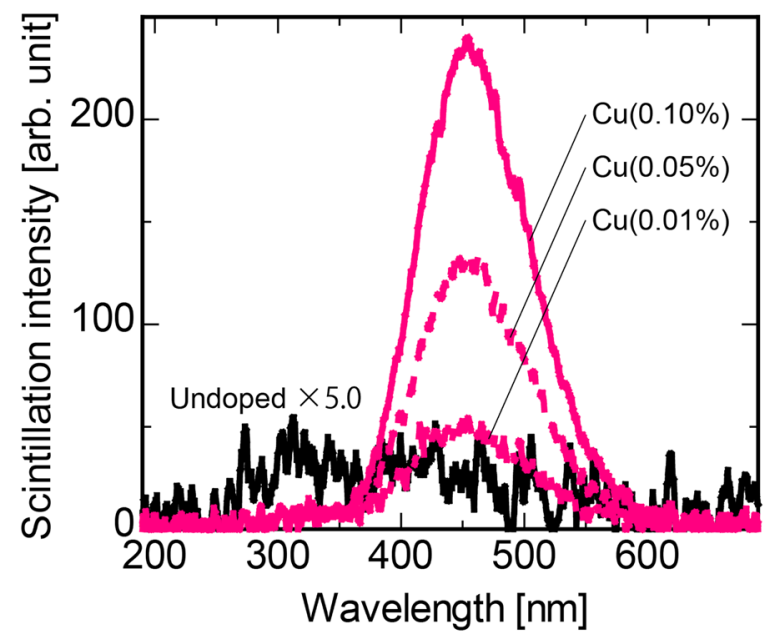

(b)

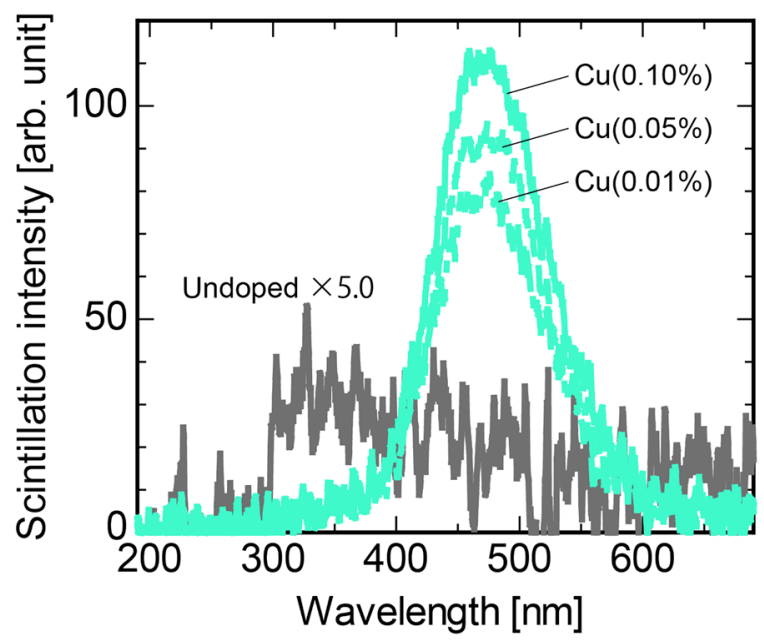

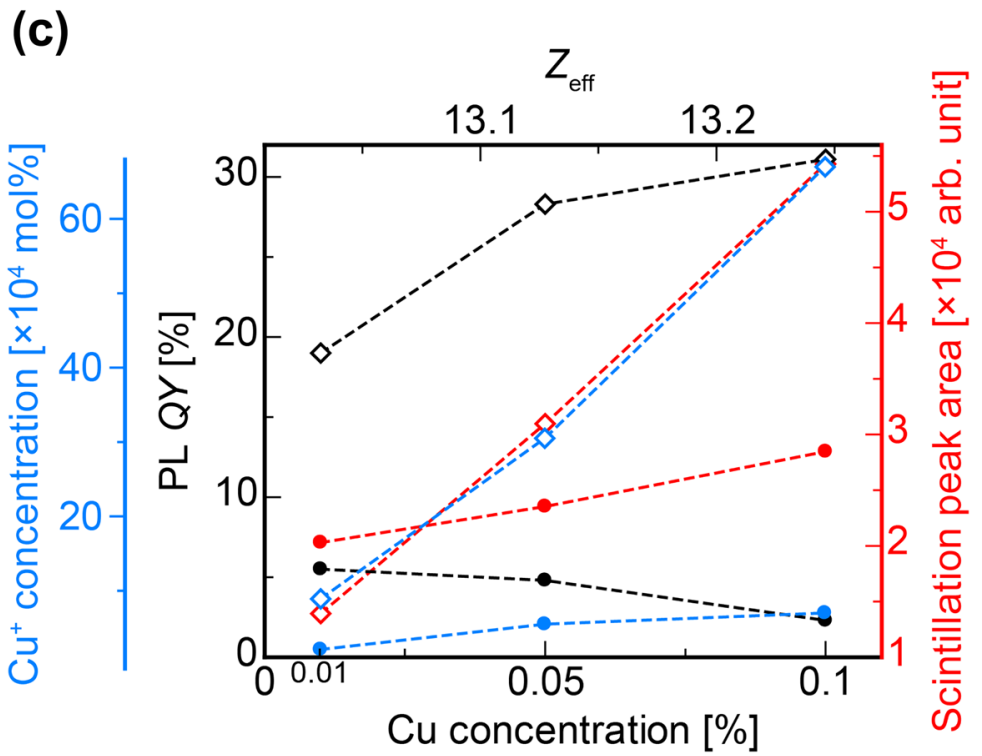

Figure 6. Scintillation properties of all the specimens. X-ray-induced scintillation spectra of the specimens prepared under (a) Ar and (b) air atmosphere. (c) Values of PL QY, the $\mathrm{Cu}^{+}$concentration, and the integrated scintillation as a function of $Z_{\text {eff }}$ and the $\mathrm{Cu}$ concentration of the specimens. Open squares and closed circles indicate $\mathrm{Cu}-\mathrm{Ar}$ and $\mathrm{Cu}$-air specimen, respectively.

$\mathrm{Cu}$ concentration causes an increase of $Z_{\mathrm{eff}}$, which in turn increases the effective absorption of X-rays. Therefore, as in Fig. 6c, the scintillation intensity of $\mathrm{Cu}$-air showed an upward trend despite the decrease in the $Q Y$.

The TSL intensity of the $\mathrm{Cu}(0.10 \%)$-Ar specimen was greater than that of the $\mathrm{Cu}(0.10 \%)$-air specimen. Here, the luminescence efficiency $\eta_{\mathrm{i}}$ in TSL is defined by the following equation ${ }^{39}$ :

$$
\eta_{\mathrm{i}}=n_{\mathrm{eh}} \eta_{\mathrm{tr}} \eta_{\mathrm{TSL}} h v \eta_{\mathrm{esc}} .
$$

Here $n_{\mathrm{eh}}, \eta_{\mathrm{tr}}, \eta_{\mathrm{TSL}}, h v$, and $\eta_{\mathrm{esc}}$ are defined as the number of e-h pairs per unit mass and per unit absorbed dose, the fraction that is captured in traps which can be thermally-stimulated, TSL efficiency, the average energy of the emitted TSL photons, and the fraction of the produced photons that will escape without being absorbed, respectively. In addition, $\eta_{\mathrm{TSL}}$ is also defined as a product of a release probability of the charges from the traps: $p$, a transport efficiency of released charges to a luminescent center: $S$, and a recombination efficiency on the luminescent center (i.e. PL QY). Now, since eacspecimen has the same base material, $n_{\mathrm{eh}}, p, S$, and $h v$, are consistent whereas $\eta_{\mathrm{i}}$ depends only on $\eta_{\mathrm{tr}}, \mathrm{QY}$, and $\eta_{\mathrm{esc}}$. Therefore, the TSL intensity of the $\mathrm{Cu}(0.10 \%)-\operatorname{Ar}$ specimen with high $Q Y$ and low self-absorption by $\mathrm{Cu}^{2+}$ was higher than that of the $\mathrm{Cu}(0.10 \%)$-air specimens. Figure $7 \mathrm{~d}$ shows that the TSL intensity increased with increasing $\mathrm{Cu}$ concentration in the $\mathrm{Cu}$-Ar specimen while the TLS 
(a)

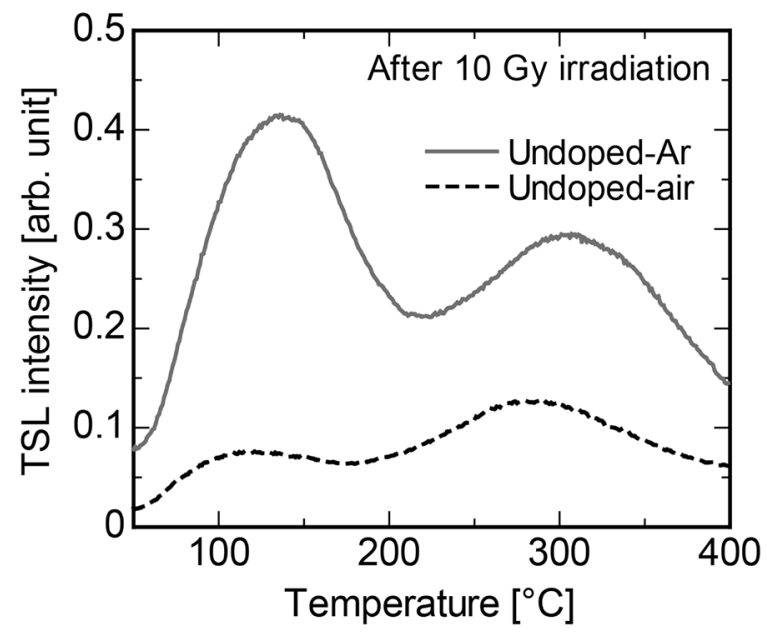

(c)

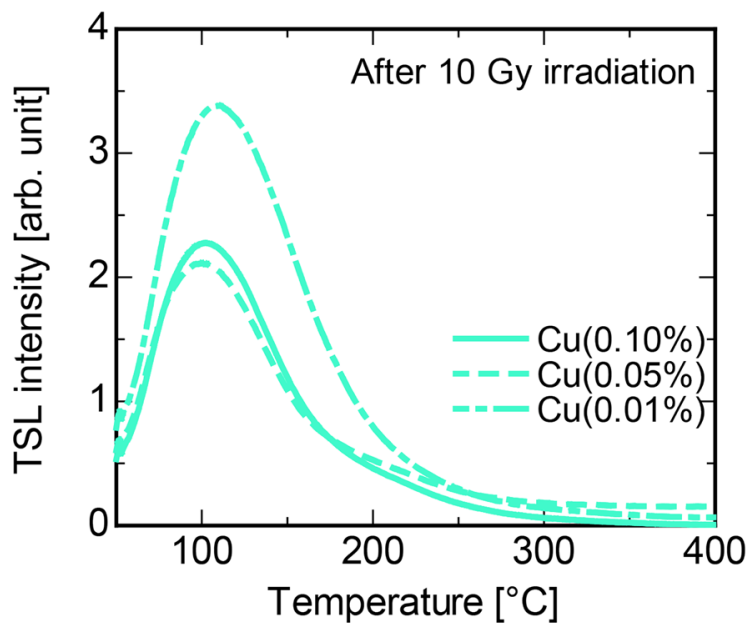

(b)

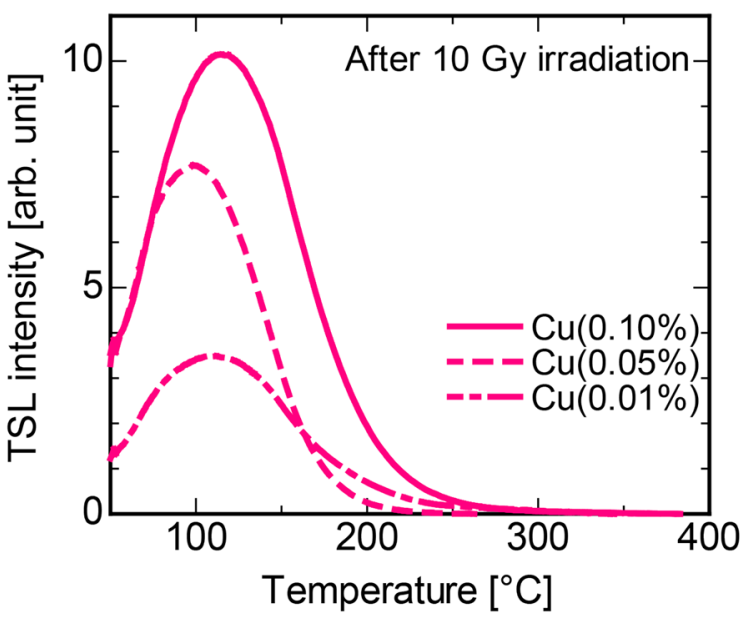

(d)

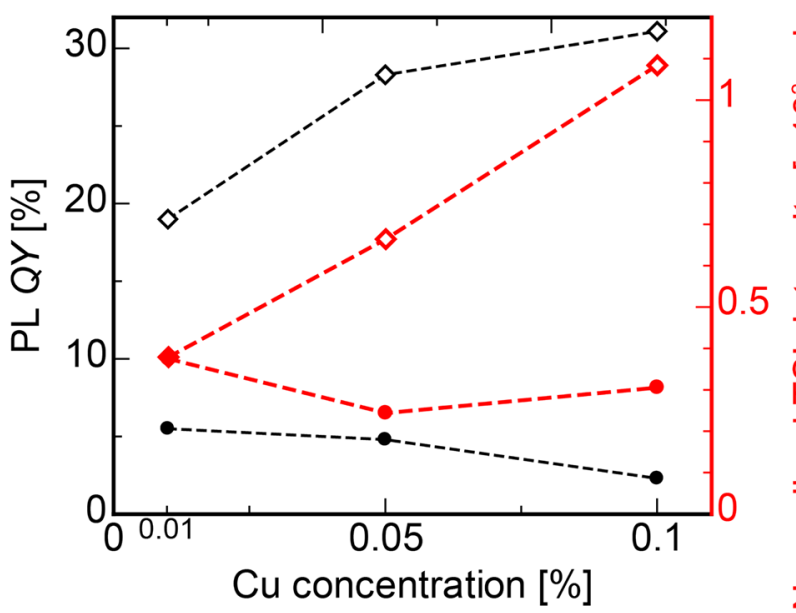

Figure 7. TSL properties of all the specimens. TSL glow curves after $10 \mathrm{~Gy}$ X-ray irradiation of the (a) undoped, (b) Cu-Ar, and (c) Cu-air specimens. (d) Correlation of PL QY in the specimens at each $\mathrm{Cu}$ concentration. Open squares and closed circles indicate $\mathrm{Cu}-\mathrm{Ar}$ and $\mathrm{Cu}$-air specimen, respectively.

intensity decreased from $0.01 \%$ to $0.05 \%$ in the $\mathrm{Cu}$-air specimen and again increased from $0.05 \%$ to $0.10 \%$. Considering the formula for $\eta_{\mathrm{i}}$, it is reasonable to think that the increase of TSL intensity depends on $\eta_{\mathrm{tr}}$. because the integrated TSL intensity is not being correlated with QY. In the $\mathrm{Cu}$-air specimens, the $\mathrm{Cu}^{+}$concentration did not increase with increasing $\mathrm{Cu}$ concentration of the specimens, however, the concentration of $\mathrm{Cu}^{2+}$ increased. This suggests that $\mathrm{Cu}^{2+}$ is likely to function as an electron trap center. As a result, the TSL intensity is predominantly contributed by the $Q Y$ at and below $0.05 \%$ while the number of electron trapping centers (i.e. $\mathrm{Cu}^{2+}$ ) dominantly contributes at and above $0.05 \%$ of $\mathrm{Cu}$ concentration.

\section{Conclusion}

The absorption spectra of the glass molten under the air atmosphere showed a pronounced optical absorption attributed to the ${ }^{2} \mathrm{E}_{\mathrm{g}}-{ }^{2} \mathrm{~T}_{2 \mathrm{~g}}$ transition of $\mathrm{Cu}^{2+}$ whereas we could scarcely observe the absorption band in the glass fabricated by melting in Ar atmosphere. Furthermore, as a result of analyzing XANES at the copper K-edge, we found that most of the copper in the glass have a low valence state $\left(\mathrm{Cu}^{+}\right)$when they are molten in the Ar atmosphere. Fabrication of a glass under a reducing atmosphere improved the PL QY of $\mathrm{Cu}^{+}$luminescence. Along with an increase of luminescence efficiency, TSL intensity of the $\mathrm{Cu}$-doped specimen improved. These results showed that the control of the melting atmosphere is effective for improving radiation-induced luminescence characteristics due to luminescent center ion such as copper which can assume several valence states. 


\section{Methods}

Preparation of undoped and $\mathrm{Cu}$-doped lithium potassium alminophosphate glass. $\mathrm{Li}_{2} \mathrm{O}-\mathrm{K}_{2} \mathrm{O}-$ $\mathrm{Al}_{2} \mathrm{O}_{3}-\mathrm{P}_{2} \mathrm{O}_{5}$ glasses were prepared by the conventional melt-quenching method using an electric furnace. The starting materials of $\mathrm{Li}_{3} \mathrm{PO}_{4}(2 \mathrm{~N}),\left(\mathrm{KPO}_{3}\right)_{\mathrm{n}}(2 \mathrm{~N})$, and $\mathrm{Al}\left(\mathrm{PO}_{3}\right)_{3}(4 \mathrm{~N})$ were uniformly mixed at the molar ratio of 10:30:60, respectively. Thus, the obtained chemical composition of glass was $8.8 \mathrm{Li}_{2} \mathrm{O}-8.8 \mathrm{~K}_{2} \mathrm{O}-17.7 \mathrm{Al}_{2} \mathrm{O}_{3}-$ $64.7 \mathrm{P}_{2} \mathrm{O}_{5}(\mathrm{~mol} \%)$. To investigate dopant concentration dependence on luminescence properties of the glass specimens, $\mathrm{Cu}_{2} \mathrm{O}(2 \mathrm{~N})$ was added to the host material to include $0,0.01,0.05$, and $0.10 \mathrm{~mol} . \%$ of $\mathrm{Cu}$ ion while the host material is dealt as $100 \%$. In this paper, 'Cu concentration' indicates the nominal value. These powders were weighed in a total amount of $10.0 \mathrm{~g}$ and mixed homogeneously using a mortar. The mixed powder was put into a Pt crucible and then melted at $1100^{\circ} \mathrm{C}$ for $20 \mathrm{~min}$ in Ar or air atmosphere. The glass preparation under an Ar gas atmosphere was carried out by the following procedure. The mixed powder in a Pt crucible was loaded into an electric tube furnace in which a $\mathrm{SiO}_{2}$ tammann tube is equipped. The tammann tube was vacuumed to less than $-0.1 \mathrm{MPa}$, and then a high purity $\operatorname{Ar}$ gas $(5 \mathrm{~N})$ was purged. The above vacuum and purge processes were repeated three times to ensure all the air was removed. During the glass melting process, a flow of Ar gas was controlled at a rate of $0.5 \mathrm{~L} / \mathrm{min}$. After the melting for $20 \mathrm{~min}$, the electric furnace was opened in air, and the $\mathrm{Pt}$ crucible was quickly taken out from the furnace using a tongue to quench the glass melt on a stainless-steel plate preheated to $200^{\circ} \mathrm{C}$. After cooling to R.T., the glasses were annealed at the glass transition temperature $T_{\mathrm{g}}$ for $1 \mathrm{~h}$ in air. Following the annealing procedure, the glass specimens were cut into the dimension of $9.0 \times 9.0 \times \sim 1.4$ $\mathrm{mm}^{3}$ and then the surfaces were mechanically polished. In this paper, we denote that the obtained glasses molten in $\mathrm{Ar}$ are $\mathrm{Cu}$-Ar specimens while those molten in air are $\mathrm{Cu}$-air specimens. The $T_{\mathrm{g}}$ of the glass specimen was determined using a TG-DTA system (Rigaku) operating at a heating rate of $10^{\circ} \mathrm{C} / \mathrm{min}$. The densities of the glass samples were determined by the Archimedes method using analytical balances (GR-120, A\&D Company, Limited). XRD patterns were measured by MiniFlex 600 (Rigaku).

Cu K-edge XANES measurement. In order to evaluate valence states of $\mathrm{Cu}$ in the glass specimens prepared under Ar and air atmosphere, we have measured XANES at the BL01B1 beamline of the synchrotron radiation facility, SPring-8. The Cu K-edge XANES measurements were carried out using a Si (111) double-crystal monochromator in the fluorescence mode using 19-SSD at R.T. Reference samples of $\mathrm{CuO}$ and $\mathrm{Cu}_{2} \mathrm{O}$, which were prepared by mixing the granular sample with boron nitride, were also measured in the transmittance mode.

Optical/luminescence properties. Transmittance spectra of the glass specimens were measured using a spectrophotometer (V670, JASCO) across a spectral range from 190 to $2700 \mathrm{~nm}$ with $1 \mathrm{~nm}$ intervals. The PL excitation/emission spectra were measured by a spectrofluorometer (FP-8600, JASCO) which equipped a Xelamp. The range of monitored wavelength was from 300 to $600 \mathrm{~nm}$ while the excitation wavelength was $260 \mathrm{~nm}$. Excitation spectra was measured from 200 to $350 \mathrm{~nm}$ when the monitored wavelength was $440 \mathrm{~nm}$. PL QYs were measured using Quantaurus-QY (C11347, Hamamatsu Photonics) at R.T. QY includes the measurement errors in $\pm 2 \%$. The monitored excitation/emission wavelength ranges were $250-350$ and $350-750 \mathrm{~nm}$ with $10 \mathrm{~nm}$ intervals, respectively. To determine an origin of luminescence, PL lifetime measurements were performed using Quantaurus-Tau (C11367, Hamamatsu Photonics).

X-ray-induced scintillation measurement. X-ray-induced scintillation spectra were measured using our laboratory-made setup ${ }^{40}$. We used an X-ray generator (XRB80N100/CB, Spellman) and CCD-based detector (Shamrock 163 monochromator and DU-420-BU2 CCD, Andor).

TSL measurement. TSL glow curves were measured using TL-2000 (Nanogray Inc.), and we set up temperature range and heating rate to $50-400{ }^{\circ} \mathrm{C}$ and $1{ }^{\circ} \mathrm{C} / \mathrm{s}$, respectively ${ }^{41}$.

Received: 26 October 2020; Accepted: 23 November 2020

Published online: 08 December 2020

\section{References}

1. McKeever, S. W. S. Optically stimulated luminescence dosimetry. Nucl. Instrum. Methods B 184, 29-54 (2001).

2. Gronchi, C. C., Cecatti, S. G. P., Pinto, T. C. N. O. \& Caldas, L. V. E. Optical decay of OSL signal of $\mathrm{Al}_{2} \mathrm{O}_{3}: \mathrm{C}$ detectors exposed to different light sources. Nucl. Instrum. Methods B 266, 2915-2917 (2008).

3. Yokota, R. \& Imagawa, H. Radiophotoluminescent centers in silver-activated phosphate glass. J. Phys. Soc. Jpn. 23, 1038-1048 (1967).

4. Miyamoto, Y. et al. Emission and excitation mechanism of radiophotoluminescence in $\mathrm{Ag}^{+}$-activated phosphate glass. Radiat. Meas. 45, 546-549 (2010).

5. Basu, S. et al. Fundamentals of PET and PET/CT imaging. Ann. N.Y. Acad. Sci. 1228, 1-18 (2011).

6. Moses, W. W. Current trends in scintillator detectors and materials. Nucl. Instrum. Methods A 487, 123-128 (2002).

7. Lecoq, P. Development of new scintillators for medical applications. Nucl. Instrum. Methods A 809, 130-139 (2016).

8. Ryzhikov, V. D. et al. Instruments and detectors on the base of scintillator crystals ZnSe(Te), CWO, CsI(Tl) for systems of security and customs inspection systems. Nucl. Instrum. Methods A 537, 424-430 (2005).

9. Sinclair, L. E., Hanna, D. S., MacLeod, A. M. L. \& Saull, P. R. B. Simulations of a scintillator compton gamma imager for safety and security. IEEE Trans. Nucl. Sci. 56, 1262-1268 (2009).

10. Abramowicz, H. et al. The response and resolution of an iron-scintillator calorimeter for hadronic and electromagnetic showers between $10 \mathrm{GeV}$ and $140 \mathrm{GeV}$. Nucl. Instrum. Methods 180, 429-439 (1981).

11. Spooner, N. J. C. et al. The scintillation efficiency of sodium and iodine recoils in a NaI(Tl) detector for dark matter searches. Phys. Lett. B 321, 156-160 (1994). 
12. Kole, M. et al. PoGOLino: a scintillator-based balloon-borne neutron detector. Nucl. Instrum. Methods A 770, 68-75 (2015).

13. Ji, Y.-Y. et al. Application of a $\mathrm{LaBr}_{3}(\mathrm{Ce})$ scintillation detector to an environmental radiation monitor. IEEE Trans. Nucl. Sci. 65, 2021-2028 (2018).

14. Watanabe, K. et al. Portable neutron detector using Ce:LiCaAlF 6 scintillator. Sens. Mater. 27, 269-275 (2015).

15. Melcher, C. L., Schweitzer, J. S., Manente, R. S. \& Peterson, C. A. Applicability of GSO scintillators for well logging. IEEE Trans. Nucl. Sci. 38, 506-509 (1991).

16. Yanagida, T., Okada, G. \& Kawaguchi, N. Ionizing-radiation-induced storage-luminescence for dosimetric applications. J. Lumin. 207, 14-21 (2019).

17. Shiratori, D. et al. Dosimetric, optical and radio-luminescence properties of Ce-doped $90 \mathrm{KPO}_{3}-10 \mathrm{Al}_{2} \mathrm{O}_{3}$ glasses. J. Mater. Sci. Mater. Electron. 30, 2464-2469 (2019).

18. Kawaguchi, N. \& Yanagida, T. Scintillation and dosimetric properties of Sn-doped $\mathrm{ZnO}_{2}-\mathrm{P}_{2} \mathrm{O}_{5}-\mathrm{SiO}_{2}$ glasses. Jpn. J. Appl. Phys. 59, SCCB21 (2020).

19. Shiratori, D., Isokawa, Y., Samizo, H., Kawaguchi, N. \& Yanagida, T. Evaluation of optical and radio-photoluminescence properties in Ag-doped $30 \mathrm{KPO}_{3}-70 \mathrm{Al}\left(\mathrm{PO}_{3}\right)_{3}$ glasses. J. Ceram. Soc. Jpn. 127, 455-461 (2019).

20. Shiratori, D., Kawaguchi, N. \& Yanagida, T. Scintillation properties of xCe:30Rb 2 O-30BaO-10AlO3-30P ${ }_{2} \mathrm{O}_{5}$ glasses. Jpn. J. Appl. Phys. 59, SCCB16 (2020).

21. Grund Bäck, L., Ali, S., Karlsson, S., Wondraczek, L. \& Jonson, B. X-ray and UV-Vis-NIR absorption spectroscopy studies of the $\mathrm{Cu}(\mathrm{I})$ and $\mathrm{Cu}(\mathrm{II})$ coordination environments in mixed alkali-lime-silicate glasses. J. Non-Cryst. Solids X 3, 100029 (2019).

22. Pickup, D. M. et al. X-ray absorption spectroscopy and high-energy XRD study of the local environment of copper in antibacterial copper-releasing degradable phosphate glasses. J. Non Cryst. Solids 352, 3080-3087 (2006).

23. Kau, L. S., Spira-Solomon, D. J., Penner-Hahn, J. E., Hodgson, K. O. \& Solomon, E. I. X-ray absorption edge determination of the oxidation state and coordination number of copper. Application to the type 3 site in Rhus vernicifera laccase and its reaction with oxygen. J. Am. Chem. Soc. 109, 6433-6442 (1987).

24. Gaur, A., Shrivastava, B. D. \& Joshi, S. K. Copper K-edge XANES of Cu(I) and Cu(II) oxide mixtures. J. Phys. Conf. Ser. 190, 012084 (2009).

25. Fukumi, K. et al. XANES study on coordination geometry of implanted $\mathrm{Cu}^{+}$ions in silica glass: dependence on doses. J. Non Cryst. Solids 271, 171-175 (2000).

26. Ehrt, D., Ebeling, P. \& Natura, U. UV Transmission and radiation-induced defects in phosphate and fluoride-phosphate glasses. J. Non Cryst. Solids 263-264, 240-250 (2000).

27. Möncke, D. \& Ehrt, D. Irradiation induced defects in glasses resulting in the photoionization of polyvalent dopants. Opt. Mater. 25, 425-437 (2004).

28. Jiménez, J. A. \& Sendova, M. Enhanced $1.53 \mu \mathrm{m}$ emission of $\mathrm{Er}^{3+}$ ions in phosphate glass via energy transfer from Cu${ }^{+}$ions. J. Appl. Phys. 116, 033518 (2014).

29. Pestryakov, A. N. et al. Study of copper nanoparticles formation on supports of different nature by UV-Vis diffuse reflectance spectroscopy. Chem. Phys. Lett. 385, 173-176 (2004).

30. Zhang, Q. et al. The reduction of $\mathrm{Cu}^{2+}$ to $\mathrm{Cu}^{+}$and optical properties of $\mathrm{Cu}^{+}$ions in $\mathrm{Cu}$-doped and $\mathrm{Cu} / \mathrm{Al}$-codoped high silica glasses sintered in an air atmosphere. Chem. Phys. Lett. 482, 228-233 (2009).

31. Jiménez, J. A. Luminescent properties of $\mathrm{Cu}^{+} / \mathrm{Sn}^{2+}$-activated aluminophosphate glass. Opt. Mater. 37, 347-351 (2014).

32. Singh, S. P. \& Kumar, A. Molar extinction coefficients of the cupric ion in silicate glasses. J. Mater. Sci. 30, 2999-3004 (1995).

33. Garćía, M. A. et al. Luminescence time decay from $\mathrm{Cu}^{+}$ions in sol-gel silica coatings. J. Lumin. 93, 253-259 (2001).

34. Jain, D., Sudarsan, V., Vatsa, R. K. \& Pillai, C. G. S. Luminescence studies on $\mathrm{ZnO}-\mathrm{P}_{2} \mathrm{O}_{5}$ glasses doped with $\mathrm{Gd}_{2} \mathrm{O}_{3}$ : Eu nanoparticles and $\mathrm{E}_{\mathrm{u}} 2_{\mathrm{O}}$ 3. J. Lumin. 129, 439-443 (2009).

35. Trukhin, A. N. Localized states in wide-gap glasses. Comparison with relevant crystals. J. Non Cryst. Solids 189, 1-15 (1995).

36. Shrikhande, V. K., Sudarsan, V., Kothiyal, G. P. \& Kulshreshtha, S. K. Photoluminescence and structural studies on $\mathrm{Na}_{2} \mathrm{O}-\mathrm{PbO}-\mathrm{SiO}{ }_{2}$ glasses. J. Non Cryst. Solids 353, 1341-1345 (2007).

37. Tiwari, B., Sudarsan, V., Dixit, A. \& Kothiyal, G. P. Effect of $\mathrm{TiO}_{2}$ addition on the optical, thermo-physical, and structural aspects of sodium alumino-phosphate glasses. J. Am. Ceram. Soc. 94, 1440-1446 (2011).

38. Shiratori, D., Isokawa, Y., Kawaguchi, N. \& Yanagida, T. Dopant concentration dependence of luminescence in Cu-doped lithium aluminophosphate glasses. Sens. Mater. 31, 1281 (2019).

39. Bos, A. J. J. On the energy conversion in thermoluminescence dosimetry materials. Radiat. Meas. 33, 737-744 (2001).

40. Yanagida, T., Kamada, K., Fujimoto, Y., Yagi, H. \& Yanagitani, T. Comparative study of ceramic and single crystal Ce:GAGG scintillator. Opt. Mater. 35, 2480-2485 (2013).

41. Yanagida, T., Fujimoto, Y., Kawaguchi, N. \& Yanagida, S. Dosimeter properties of AlN. J. Ceram. Soc. Jpn. 121, 988-991 (2013).

\section{Acknowledgements}

This work was supported by Grant-in-Aid for Scientific Research A (17H01375), B (18H03468 and 19H03533), Early-Career Scientists (20K20104), and JSPS Fellows (20J23225). The synchrotron radiation experiments were performed at BL01B1 of SPring-8 with the approval of the Japan Synchrotron Radiation Research Institute (JASRI) (Proposal No. 2019A1082 and 2019B1562). Cooperative Research Project of Research Center for Biomedical Engineering is also acknowledged.

\section{Author contributions}

D.S. and H.M. formulated the research project and performed the materials preparation. H.M. performed the XANES analysis. D.S., T.K., D.N., N.K., and T.Y. measured the X-ray-induced scintillation. D.S., H.M., T.K., and G.O. wrote the paper. All authors discussed the results.

\section{Competing interests}

The authors declare no competing interests.

\section{Additional information}

Supplementary information is available for this paper at https://doi.org/10.1038/s41598-020-78510-z.

Correspondence and requests for materials should be addressed to D.S.

Reprints and permissions information is available at www.nature.com/reprints.

Publisher's note Springer Nature remains neutral with regard to jurisdictional claims in published maps and institutional affiliations. 
(c) (i) Open Access This article is licensed under a Creative Commons Attribution 4.0 International cc) License, which permits use, sharing, adaptation, distribution and reproduction in any medium or format, as long as you give appropriate credit to the original author(s) and the source, provide a link to the Creative Commons licence, and indicate if changes were made. The images or other third party material in this article are included in the article's Creative Commons licence, unless indicated otherwise in a credit line to the material. If material is not included in the article's Creative Commons licence and your intended use is not permitted by statutory regulation or exceeds the permitted use, you will need to obtain permission directly from the copyright holder. To view a copy of this licence, visit http://creativecommons.org/licenses/by/4.0/.

(C) The Author(s) 2020 